\title{
Female breeding dispersal in wolverines, a solitary carnivore with high territorial fidelity
}

\author{
Malin Aronsson ${ }^{1}$ (D) . Jens Persson ${ }^{1}$
}

Received: 31 March 2017 / Accepted: 8 January 2018 / Published online: 26 January 2018

(C) The Author(s) 2018. This article is an open access publication

\begin{abstract}
Individuals' fidelity to an area provides insight into the stability of the spatial and temporal organisation of animals. Territorial fidelity is often influenced by reproductive success, age, the dispersion and predictability of resources, and intraspecific competition. We examined between-year territorial fidelity in wolverines (Gulo gulo), using location data from 47 individuals collected during 1993-2013 in northern Sweden, to assess the stability of the spatial organisation of this solitary carnivore. For females, we also determined residency status from 1 year to the next. The study population is characterized by a stable distribution of resident individuals, with both males and females showing higher fidelity at the total territory level compared to more intensively used core areas. In $86 \%$ of the yearly residency status estimates $(n=122)$, the female remained stationary. In the remaining $14 \%$ of the cases, females either vacated their territory ( $8 \%$ of residency statuses), or expanded into a neighbouring territory (6\% of residency statuses). We documented six cases of breeding dispersal, representing one of the few known cases of breeding dispersal in longlived large mammals. We suggest that this high territorial fidelity is enabled by wolverines' caching and scavenging behaviours, which buffer the unpredictable and large spatiotemporal variation in resource abundance in this low-productivity area. Breeding dispersal may occur due to competition for high-quality territories in this saturated population, where females are forced to abandon their territory by competitors or bequeath territories to offspring. This study further highlights the complexity of the social and spatial dynamics for solitary carnivores.
\end{abstract}

Keywords Floater $\cdot$ Social system $\cdot$ Territoriality $\cdot$ Space use $\cdot$ Home range

\section{Introduction}

Individuals' fidelity to an area reflects the stability of the spatial organisation of animals (Switzer 1993; Adams 2001), and interannual variation in space use patterns can influence both population structure and dynamics (Terraube et al. 2015; Uboni et al. 2015). Home range fidelity is generally associated to dispersion, predictability and depletion rate of resources, as well as reproductive success, age and competition (Moorhouse and Macdonald 2005, Kirk et al. 2008; Edwards et al. 2009; Terraube et al. 2015). In solitary territorial species, space use is primarily driven by resource

Malin Aronsson

malin.aronsson@slu.se

1 Grimsö Wildlife Research Station, Department of Ecology, Swedish University of Agricultural Sciences, SE-73091 Riddarhyttan, Sweden competition over access to food or the opposite sex (Sandell 1989; Aronsson et al. 2016). Territorial fidelity is beneficial because it allows individuals to become familiar with resources in an area, enhancing survival and reproductive success (Switzer 1993; Kirk et al. 2008). Furthermore, for species that aggressively defend territories, movement into unfamiliar areas increases mortality risk (Isbell et al. 1990; Stamps and Krishnan 2001). Despite this, some individuals may vacate an established territory and perform breeding dispersal, defined as the permanent movement of individuals, which have reproduced, between subsequent breeding sites (Greenwood 1980). Breeding dispersal has mostly been documented in birds (e.g. Greenwood and Harvey 1982; Terraube et al. 2015), and although it occurs in mammals (e.g. Berteaux and Boutin 2000; Jerina et al. 2014), it has rarely been documented in larger long-lived mammals (Jerina et al. 2014).

Breeding dispersal may be a consequence of reproductive failure, mate loss or an attempt to acquire a higher-quality territory (Wauters et al. 1995; Forero et al. 1999; Pasinelli et al. 2007). It can also result from intraspecific competition, 
when resident individuals are evicted or disperse to take over a new territory (Pasinelli et al. 2007; Mattisson et al. 2013). Breeding dispersal has also been considered as a form of parental investment when the territory is bequeathed to an offspring to enhance offspring survival and reproductive success (Lindström 1986; Berteaux and Boutin 2000). Moreover, some individuals that vacate a territory may become floaters (Smith 1978), forming a reservoir of individuals that can occupy vacant territories when they become available and thus influence population dynamics (Penteriani et al. 2011).

Long-term, individual-based ecological studies are essential to obtain information about between-year variation in space use and spatial organisation (Pelton and van Manen 1996; Clutton-Brock and Sheldon 2010). In this study, we use location data from 47 adult wolverines (Gulo gulo) monitored during 20 years (1993-2013) in northern Sweden. The wolverine is a solitary carnivore with a polygamous mating system (Hedmark et al. 2007), intrasexual territoriality (Persson et al. 2010; Inman et al. 2012a) and male-biased natal dispersal (Vangen et al. 2001; Flagstad et al. 2004). Wolverines occupy arctic tundra and boreal forest zones of Eurasia and North America (Copeland et al. 2010) and are adapted to harsh environmental conditions with low productivity by being an opportunistic generalist predator and scavenger that caches food for later use (Inman et al. 2012b; Mattisson et al. 2016). Wolverine female reproductive success is influenced by winter food availability as well as age-related reproductive costs, where the probability to successfully reproduce 2 years in a row declines with age (Persson 2005; Rauset et al. 2015). In northern Sweden, wolverines primarily feed on migratory, semi-domestic reindeer (Rangifer tarandus) (Mattisson et al. 2011; Mattisson et al. 2016) managed by indigenous Sámi reindeer herding communities (Persson et al. 2009).

The aim of this study was to assess the stability of wolverine spatial organisation by examining individual territorial fidelity from 1 year to the next. To account for the possibility that factors determining space use differ between intensively used areas compared to the total territory (Aronsson et al. 2016), we measured site fidelity at two spatial scales: (i) total territory and (ii) core area. We also examined between-year changes in female residency status, i.e. did they remain resident or did they permanently leave an established territory. Breeding dispersal may occur to enhance future reproductive success (Wauters et al. 1995; Pasinelli et al. 2007), or as a consequence of decreased reproductive potential with age (Berteaux and Boutin 2000). Therefore, we considered the influence of previous reproductive performance and age on fidelity for wolverine females. Territorial fidelity is generally predicted to be low in unpredictable environments with low and variable resource abundance (Switzer 1993; Maher and Lott 2000; Moorhouse and Macdonald 2005; Edwards et al. 2009). Still, we predict that wolverines exhibit high territorial fidelity because of their food-caching behaviour that buffers temporal fluctuations in food availability and thus, promotes territoriality and site fidelity even when resources in the environment are unpredictable (Tye 1986; Maher and Lott 2000; Eide et al. 2004).

\section{Material and methods}

\section{Study area and animal capture}

The study was carried out in a $7000-\mathrm{km}^{2}$ area in and around Sarek National Park in northern Sweden (Kvikkjokk $67^{\circ} 00^{\prime}$ $\mathrm{N}, 17^{\circ} 40^{\prime} \mathrm{E}$ ). The climate is continental with cold winters ($13^{\circ} \mathrm{C}$ in January) and medium warm summers $\left(14{ }^{\circ} \mathrm{C}\right.$ in July) and the ground is usually snow covered from November to May. The area is characterized by deep valleys, glaciers and high alpine plateaus with peaks up to $2000 \mathrm{~m}$ a.s.l.. Mountain birch (Betula pubescens) forms the tree line at $600-700 \mathrm{~m}$ a.s.l. (for a detailed description of the study area, see Rauset et al. (2015)). The area consists of important spring and summer grazing pastures for semi-domestic reindeer. During winter, most reindeers are moved to winter grazing grounds to the east of the study area (Danell et al. 2006), resulting in a large temporal and spatial variation in reindeer density.

We used wolverine location and reproductive data collected from 1993 to 2013. Wolverines were captured and immobilized using ethics-approved handling protocols (see Persson et al. 2010). Animals were fitted with VHF collars (1993-1995: MOD315, Telonics. USA), intraperitoneal VHF transmitters (1996-2013: IMP/210/L, IMP/300/L or IMP/ 400/L, Telonics. USA) or GPS collars (2003-2006: Televilt PosrecTM C300, TVP positioning AB, Sweden; 2008-2013 GPS plus mini, Vectronics Aerospace, Germany). Female reproductive status and location of natal den sites (hereafter dens) was confirmed using a combination of radio tracking, snow tracking and visual observations (see Persson et al. 2006). Reproductions were classified as successful if the cubs survived until June (3-4 months old) and unsuccessful if the female showed denning behaviour but did not have cubs in June or did not reproduce. We aimed to capture and equip all cubs with intraperitoneal transmitters and monitor them throughout their life; consequently, a large part of the individuals were of known age.

\section{Spatial analysis}

Only resident animals $\geq 3$ years old were included in the analysis because wolverines in the study population rarely breed prior to 3 years (Rauset et al. 2015). We estimated annual space use for each individual as the annual utilization distribution (UD) using the fixed-kernel method with the reference bandwidth (Worton 1989) within the "adehabitatHR" package 
(Calenge 2006) for $\mathrm{R}$ ( $\mathrm{R}$ Core Team 2014). Years were defined as calendar years. The number of locations acquired per individual and year varied extensively during the study period as telemetry technology developed. To reduce biases from different sampling frequencies (Börger et al. 2006), we randomly sampled one location/day for individuals with multiple daily locations. We only calculated UDs for individuals monitored for $\geq 6$ months during $\geq 2$ years with $\geq 20$ yearly locations (Persson et al. 2010; Rauset et al. 2015); in this study, mean $( \pm$ SE) of annual locations per individual was $146 \pm 15$. From the UD, a specific proportion (isopleth) of the animal's use of space can be retained; we used the $90 \%$ isopleth as the annual territory and the $50 \%$ isopleth as the core area (Rauset et al. 2015). We quantified fidelity by estimating the overlap between annual UDs using the volume of intersection index (VI) for both the territory and core area levels (Millspaugh et al. 2004). VI values range from 0 (no overlap) to 1 (identical UDs). We calculated VI for subsequent years, or year $t$ and $t+$ 2 if location data from year $t+1$ was missing ( 5 out of $62 \mathrm{VI}$ estimates). Because annual territory sizes do not differ for females with or without cubs (Persson et al. 2010), we calculated VI between years independent of female reproductive status. During part of the study period (i.e. 1999-2004), the focus of the project was to monitor yearly survival, reproductive success and denning behaviour of the resident females within the study area. Hence, females were intensively monitored during the denning period (Feb-May; cf. Rauset et al. 2015 ) while there are relatively infrequent locations from $\geq$ 6 months/year for these females. Consequently, for females, we also used distances between den sites as a measurement of fidelity. We calculated distances between den sites in subsequent years or year $t$ and $t+2$ if the female did not reproduce in year $t+1$ (22 out of 90 den distances). In total, we obtained 129 interannual fidelity estimates for 5 males (7 VI) monitored for an average of 2.6 years $\pm 0.6 \mathrm{SE}$ (range 2-5) and 42 females (55 VI and 90 den distances) monitored for $4.5 \pm$ 0.4 years (range $2-11$ ).

The closest distance between neighbouring females' den sites used in the same year was $4.6 \mathrm{~km}$ (Aronsson 2017). Consequently, we considered females to have conducted breeding dispersal if the VI estimate or locations showed that she moved from her territory, she reproduced again $>4.5 \mathrm{~km}$ from her previous den site and her previous territory was occupied by a new individual. Furthermore, females that did not reproduce after moving were considered to have reestablished when subsequent space use pattern showed that they became stationary in a new area. We used reproductive success to obtain a measurement of territory quality (Garshelis 2000; Stephens et al. 2015). For this, we used the locations of all den sites for collared individuals and den sites from the national monitoring program (i.e. since 1996, wolverine den sites have been recorded in the Swedish national monitoring program for large carnivores, see Aronsson and Persson
(2016)). For each female, we calculated the total number of den sites that had been documented within $2.1 \mathrm{~km}$ of her current den site (i.e. $2.1 \mathrm{~km}$ is the mean distance between consecutive den sites for stationary females in this study area, see "Results" section) or centre point of locations for females that did not reproduce $(n=2)$. We calculated local denning frequency for each area and year (local denning frequency (LDF)) as the total number of den sites divided by the time the area had been monitored (i.e. 18 years; 1996-2013). Because this measurement is based on successful reproductions, an important fitness component, within the territory, we argue that this is a good measurement of territory quality.

\section{Statistical analysis}

We used generalized linear mixed models with a beta error distribution in the glmmADMB package (Skaug et al. 2014) in $\mathrm{R}$ with $\mathrm{VI}$ as the response variable. Individual identity was fitted as a random effect in all models to account for repeated measurements. We used isopleth level as a covariate to test if fidelity differed between territory and core area level. Due to the low sample size for males $(n=7)$, we did not conduct any statistical analysis for differences between sexes. For females, we included age and reproductive success in year $t$ (two-level factor; successful and unsuccessful reproduction) as covariates. Candidate models were compared using the sample size-corrected Akaike Information Criterion $\left(\mathrm{AIC}_{\mathrm{c}}\right)$ and $\mathrm{AIC}_{\mathrm{c}}$ weights $\left(w_{i}\right)$. Means are presented with standard errors unless otherwise stated.

\section{Results}

Female and male wolverines had similar overlap (volume of intersection; VI) patterns and showed higher between-year fidelity for the annual territory compared to core areas (Fig. 1; $0.60 \pm 0.03$ vs. $0.44 \pm 0.03$ for females, and $0.55 \pm 0.03$ vs. $0.42 \pm 0.1$ for males, respectively; improvement in $\mathrm{AIC}_{\mathrm{c}}$ for overlap model including isopleth level [i.e. 90 and 50\%] compared to model without: females $=18$ and males $=3.2$ ). We determined female residency status from 1 year to the next in 122 territories, and in 105 (86\%) of these, the female remained stationary; hence, wolverine females showed high territorial fidelity. Eight of the 42 females vacated an established territory once $(n=7)$ or twice $(n=1)$, resulting in a total of nine occasions when a resident female moved from her territory (Table 1, Fig. 2). These moving females re-established in a new territory in seven of these nine cases (Table 1). In all but one of these, the female reproduced in the new territory and thus conducted breeding dispersal (Figs. 2 and 3 ). Floating behaviour was exhibited by the two females that did not re-establish and one breeding dispersal female before she re-established (Table 1, Fig. 2). Five 
Fig. 1 Frequency distributions of volume of intersection (VI) values showing: territory (a) and core area (b) fidelity for female and male wolverines in northern Sweden during 1993-2013. VI represents how similar space use was between years (i.e. VI value of 0 represents no overlap and VI represents identical space use). Females are divided depending on residency status; stationary (light grey), expanding (medium grey) and breeding dispersing or floating (dark grey) (a)

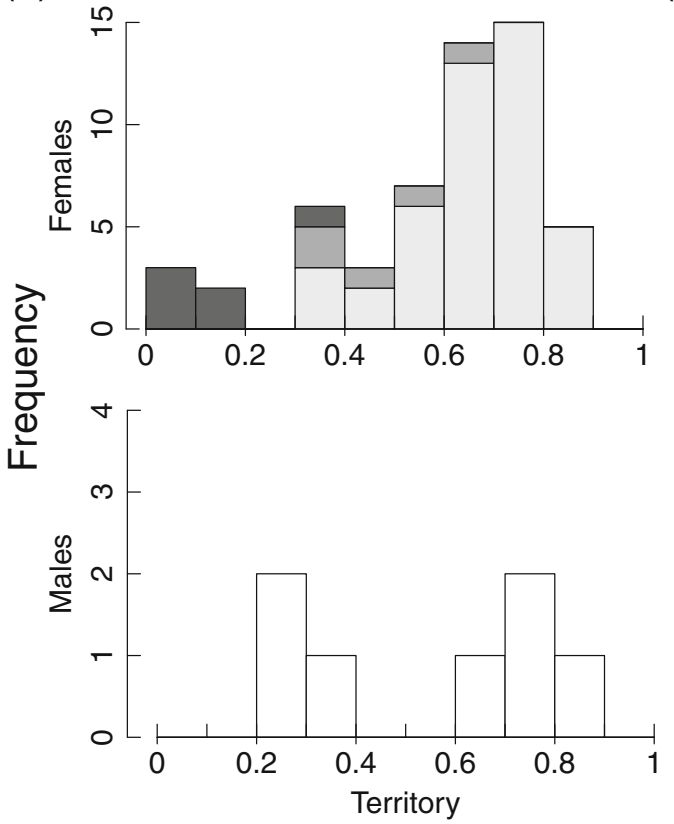

(b)
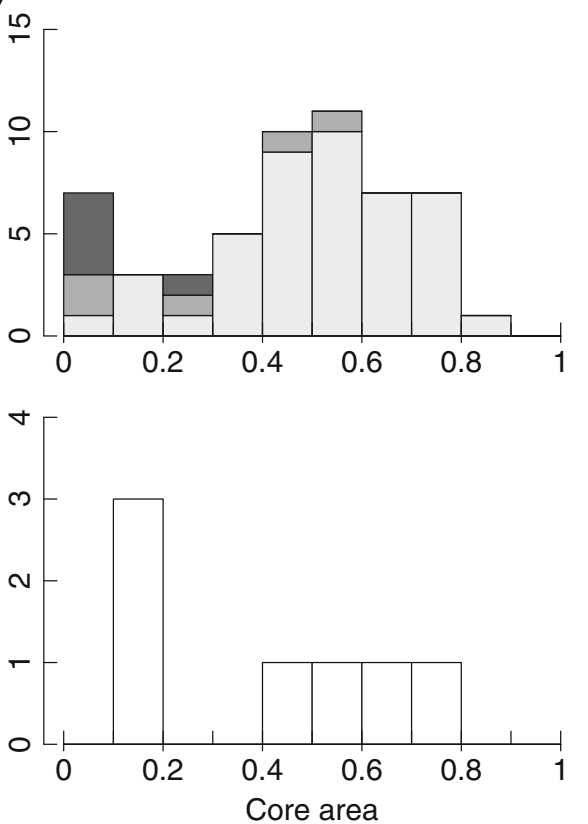

Volume of Intersection

additional females expanded their territory once $(n=3)$ or twice $(n=2)$ into a neighbouring territory after the neighbouring female died, resulting in reduced overlap. Thus, they subsequently occupied an area previously occupied by two or three females (hereafter called "expanding;" Fig. 4(a, c)).

The mean distance between consecutive natal den sites for stationary females (excluding expanding females) was $2.1 \pm$ $0.2 \mathrm{~km}(n=79)$, for breeding dispersing females $9.8 \pm 0.8 \mathrm{~km}$ $(n=6)$ and for expanding females $9.1 \pm 2.3(n=5)$ (Fig. 5). Mean local denning frequency (LDF) for stationary females was $0.21 \pm 0.02$. To obtain a relative quality estimate for territories that were vacated in relation to where females reestablished, we used the difference in LDF for these sites from the mean for stationary females (Table 1). Of the seven females that re-established, there was no consistent pattern in how their LDF changed from before and after re-establishment: the LDF of three females improved; for three females, it diminished; and for one female, LDF did not change. However, only two females re-established in a territory with better quality than the mean for stationary females (Table 1). The mean territory and core area VI for stationary females was
Table 1 Individual females that moved from an established territory during the study period (1993-2013), total time they were monitored, age when moving, residency status (floater $(\mathrm{F})$, breeding dispersal (BD) or re-established $(\mathrm{R})$ ), reproductive performance before and after move and time from move to first reproduction in second territory. Relative local denning frequency (LDF) shows the difference in LDF for the first and second territory from the mean LDF for stationary females $(0.21 \pm$ $0.022)$

\begin{tabular}{|c|c|c|c|c|c|c|c|c|}
\hline ID & $\begin{array}{l}\text { Years } \\
\text { monitored }\end{array}$ & $\begin{array}{l}\text { Age when } \\
\text { moving }\end{array}$ & $\begin{array}{l}\text { Residency } \\
\text { status }\end{array}$ & $\begin{array}{l}\text { Reproductive performance } \\
\text { before moving }\end{array}$ & $\begin{array}{l}\text { Reproduction in } \\
\text { new territory }\end{array}$ & $\begin{array}{l}\text { Time } \\
\text { (years) }\end{array}$ & $\begin{array}{l}\text { Relative LDF } \\
\text { first territory }\end{array}$ & $\begin{array}{l}\text { Relative LDF } \\
\text { second territory }\end{array}$ \\
\hline F9530* & 5 & 4 & $\mathrm{~F}^{\mathrm{a}}$ & Success & & $3 *$ & 0.35 & \\
\hline F9530 & “ & 5 & $\mathrm{BD}^{\mathrm{a}}$ & & Yes & & & -0.15 \\
\hline F9530 & “ & 6 & $\mathrm{BD}$ & Fail & Yes & 1 & -0.15 & -0.04 \\
\hline F9646 & 2 & 7 & $\mathrm{BD}$ & Fail & Yes & 1 & -0.09 & 0.02 \\
\hline F9870 & 5 & 6 & $\mathrm{BD}$ & Success & Yes & 1 & 0.02 & -0.15 \\
\hline F03167 & 3 & $?$ & $\mathrm{BD}$ & Success & Yes & 2 & -0.15 & 0.02 \\
\hline F05202 & 3 & $?$ & $\mathrm{BD}$ & Success & Yes & 2 & -0.15 & -0.15 \\
\hline F9525 & 7 & 9 & $\mathrm{R}$ & Success & No & - & 0.02 & -0.21 \\
\hline F9312 & 2 & 6 & $\mathrm{~F}$ & Success & - & - & -0.15 & - \\
\hline F9315 & 2 & 4 & $\mathrm{~F}$ & Success & - & - & 0.35 & - \\
\hline
\end{tabular}

${ }^{a}$ F9530 showed were classified as floater after more before establishing and reproducing in a new territory (see Fig. 2) 

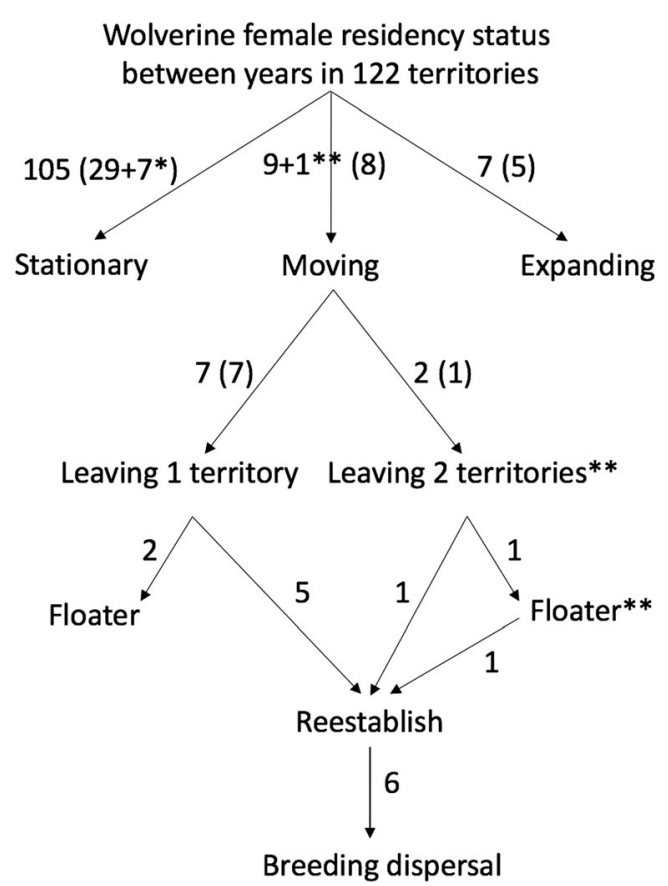

Fig. 2 Summary of residency status from 1 year to the next in 122 territories for a total of 42 adult wolverine females monitored for $\geq$ 2 years during 1993-2013 in northern Sweden. Next to each arrow are indicated number of territories and (number of females). Seven females* were stationary before and/or after moving/expanding, hence these are included in both the stationary and moving female categories. One female moved from two territories during the study period, and before reestablishing the first time, she was defined as floater during 1 year**. Consequently, although only nine territories were vacated during the study period residency status were classified as moving in $(9+1)^{* *}$ occasions $(+1$ due to floating followed by breeding dispersal in one territory)

$0.66 \pm 0.02$ and $0.52 \pm 0.03$, respectively, and VI for moving and expanding females was $0.21 \pm 0.05$ and $0.09 \pm 0.03$, respectively (Fig. 1). By including all females in the analysis, we found that both territory and core are fidelity was negatively affected by previous reproductive performance (i.e. females that successfully reproduced the first year included in the overlap measurement had lower VI values than females that did not reproduce the first year; Table 2a). However, excluding females that dispersed or showed floating behaviour from the analysis removed this effect of reproductive success on fidelity (Table $2 b$ ). There was no effect of female age on territory or core area overlap (Table 2c).

\section{Discussion}

As predicted, wolverines showed high territorial fidelity, as females remained stationary in their territory between years in $86 \%$ of the residency status estimates $(n=122)$. This suggests that the population is characterized by a stable spatial distribution of resident individuals. However, we found six occasions of breeding dispersal, representing the first

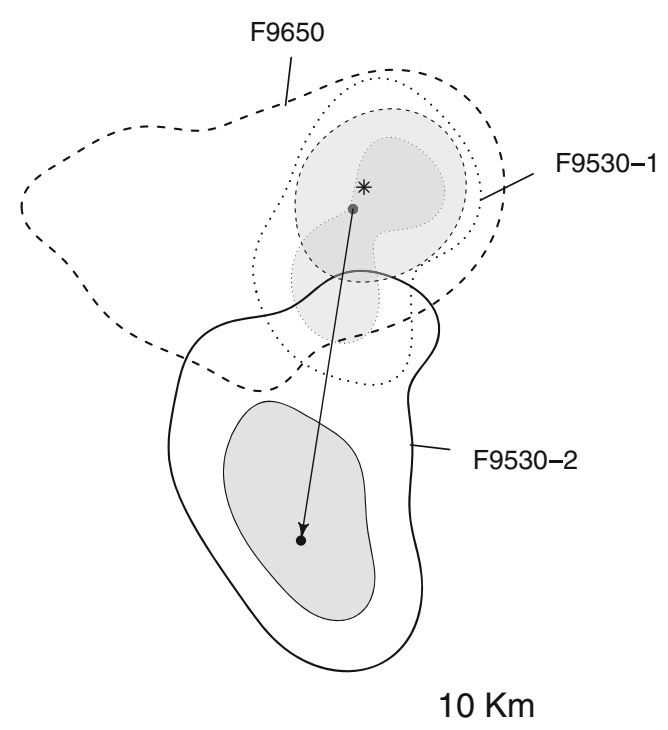

Fig. 3 Breeding dispersal by wolverine female F9530. F9530 reproduced successfully in a territory (F9530-1; dotted line) in year 1 . She subsequently left her first territory and re-established and reproduced in a new territory (F9530-2; solid line) in year 2. Den sites of F9530 are represented by filled circle $(\bullet)$; arrow shows dispersal direction. Simultaneously, F9650 established a territory (dashed line) and reproduced $(*)$ in the former area of F9530. Core areas are shown in grey with the same outline as corresponding territory

documentation of wolverine female breeding dispersal, and one of the few in long-lived, large mammals (Jerina et al. 2014). This behaviour creates infrequent exceptions to the stable spatial organisation and adds important knowledge regarding the complexity of spacing behaviour in large mammals in general and wolverines in particular.

Territorial fidelity is predicted to be low in habitats where food resources are low, variable and unpredictable and deplete fast (Wauters et al. 1995; Kirk et al. 2008; Edwards et al. 2009). This corresponds to the characterization of wolverine habitat in general (Persson 2005; Inman et al. 2012b), and particularly in northern Scandinavia where wolverines are highly dependent on migrating reindeer. Reindeer movements are influenced by seasonal snow conditions and Sámi reindeer herding practices (Persson 2005). Thus, prey availability is unpredictable and varies both within and among years, resulting in large territory sizes with high individual variation (Persson et al. 2010). However, food caching is an integral part of wolverine biology (Inman et al. 2012b; Mattisson et al. 2016), which buffers against depletion, unpredictability and variation in prey availability. As a consequence, food caching can be an important factor promoting the observed high territorial fidelity in wolverines despite the unpredictable environment (Tye 1986; Eide et al. 2004). In addition, occurrence of more efficient predators, such as the Eurasian lynx (Lynx lynx), provides wolverines with a relatively consistent availability of carcasses for direct consumption and caching (Mattisson et al. 2011). This decreases the variation and 
(a)

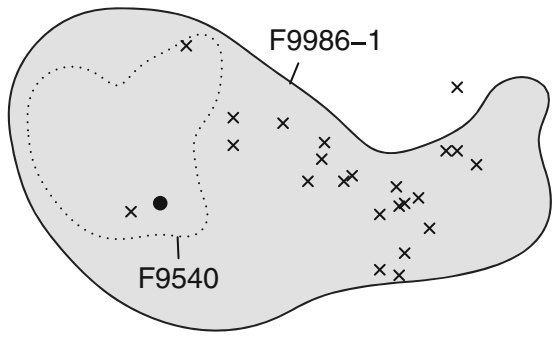

(b)

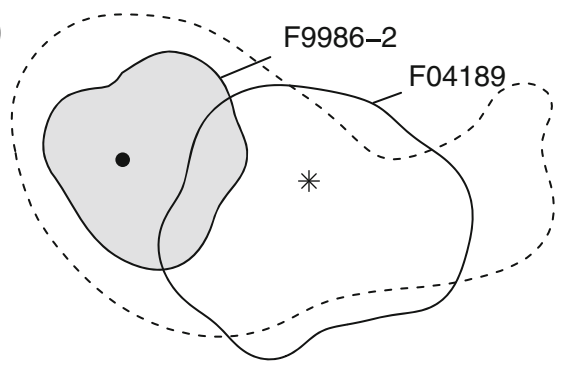

(c)

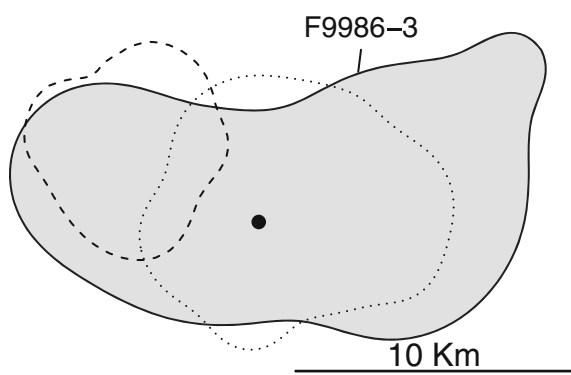

Fig. 4 Territory expansion and split by wolverine female F9986. (a) F9986 expanded her territory after the death of the neighbouring female F9540 in 2003; telemetry locations for F9986 before expansion are represented by crosses (x). Consequently, the new territory of F9986 (F9986-1; grey) covers an area previously containing two female territories. Filled circle $(\bullet)$ represents the den site of F9986 in 2004 where she gave birth to a female offspring (F04189). (b) In 2007, the area is split between mother (F9986-2; grey) and daughter (F04189); they are both reproducing in 2008 . Filled circle $(\bullet)$ represents den site of F9986 and star (*) den site of F4189. (c) After the death of F04189 (lethal control June 2008), F9986 expands again (F9986-3; grey). Filled circle $(\bullet)$ represents the den site of F9986 in 2009, and she is poached later that same year

unpredictability in food availability and enhances wolverine reproductive success (Rauset et al. 2015; Mattisson et al. 2016). Our study area is largely saturated with wolverine territories, resulting in few available areas to settle (Persson et al. 2010; Aronsson 2017). Territories are maintained by patrolling in combination with marking and aggressive behaviour during encounters (Persson et al. 2003, 2009, 2010), and both subadult and adult wolverines are killed by conspecifics (Krebs et al. 2004; Persson et al. 2009). Consequently, the high potential cost associated with exploratory movements might contribute to the high territorial fidelity. Furthermore, the area is characterized by distinct features, such as mountains, deep valleys and rivers, which form natural territory borders that might facilitate territorial defence (Eason et al. 1999). This could confine individuals to established territories and thus further promote territorial stability in time and space.

Fidelity was lower at the core area level than at the territory level for both males and females, suggesting that it is critical to maintain the outer territory boundary to secure long-term resources (Aronsson et al. 2016). In contrast, the extent of the most used area within the territory (i.e. core area) presumably varies among years because of spatial fluctuations in key resources. For instance, the spatial distribution of live reindeer and carcasses could greatly vary within and among years due to the nomadic behaviour of reindeer (Mattisson et al. 2016). In addition, female core areas could vary among years depending on their reproductive status and interannual variation in den site location. Male wolverines have territories that are several times larger than females (Persson et al. 2010). Larger areas are more difficult to defend from intrusion, which could decrease territorial fidelity (Jetz et al. 2004). However, both males and females in our study showed high mean overlap values between years. For males, this could be a result of our low sample size (i.e. five unique individuals). Of the monitored males, three individuals showed lower overlap than the other two (Fig. 1). One male retreated from parts of his territory when a neighbouring male moved in, indicating that the former might have been actively pushed away by the latter (i.e. resulting in low overlap values for both males). The third male appeared to be abandoning his territory at the end of his monitoring period.

Although wolverine females generally exhibit high territorial fidelity, we found that $8 \%$ of territories were vacated between years and $6 \%$ of territories were expanded (Fig. 2). If insufficient resources were the main reason for females to vacate a territory, we would expect them to have low reproductive success prior to moving (Pasinelli et al. 2007). Yet, on seven of nine occasions, the moving females reproduced successfully the last year monitored before vacating her territory (Table 1), which suggests that reproductive failure is not the main factor causing established females to abandon a territory. That most females successfully reproduced before vacating their territory also explains the overall negative effect of reproductive success on both territory and core area fidelity (i.e. lower VI for females that successfully reproduced; Table 2a), as this effect was considerably diminished when dispersing, expanding and floating females were excluded (Table 2b). Five of the seven females that re-established reproduced the first year in the new territory. Considering the high reproductive frequency before and after dispersal (78 and $71 \%$, respectively) compared to the average reproductive frequency in the population (53\%; Persson et al. 2006) suggests that most females that moved were in prime condition (Rauset et al. 2015) (Table 1). Thus, possible reasons for their dispersal are to obtain a territory of higher quality (cf. Wauters et al. 1995). Our measure of relative quality of territories that were vacated 


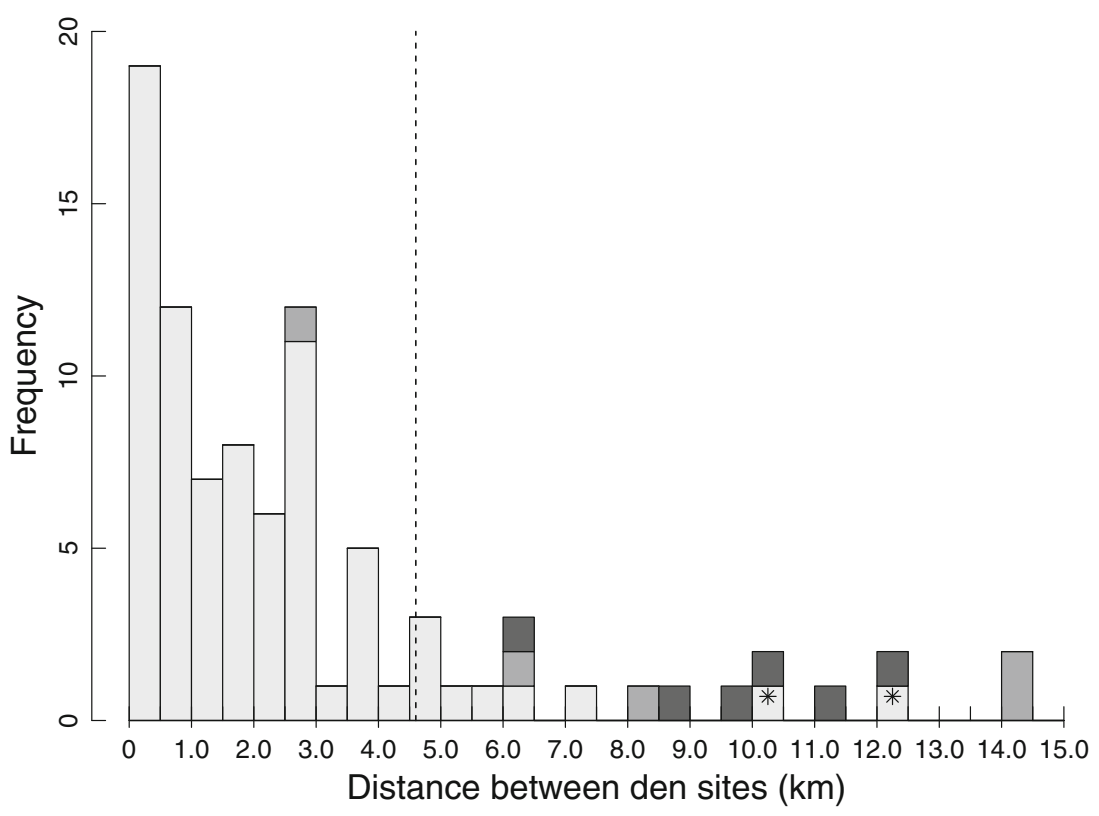

Fig. 5 Frequency distribution of distances $(\mathrm{km} ; n=90)$ between yearly den sites for wolverine females in northern Sweden during 1993-2013. Females are divided into stationary ( $n=79$; light grey), expanding $(n=5$; medium grey) and breeding dispersing ( $n=6$; dark grey). One female repeatedly used den sites at opposite ends of a large and elongated territory resulting in two large den distances (indicated by * *). By

and re-established, respectively, showed an inconsistent pattern (Table 1). If territorial abandonment and re-

Table 2 Candidate models relating wolverine female interannual territory and core area volume of intersection (VI) to reproductive success (Repro; difference of successful reproduction from unsuccessful reproduction) for all VI $(n=55)$ (a), only VI for stationary females (i.e. excluding breeding dispersal, expanding and floating; $n=46$ ) (b), and age for females with known age $(n=21)$ (c). Models are ranked based on sample size-corrected $\mathrm{AIC}\left(\mathrm{AIC}_{\mathrm{c}}\right)$, difference in $\mathrm{AIC}_{\mathrm{c}}$ relative to the highestranked model $\left(\triangle \mathrm{AIC}_{\mathrm{c}}\right)$ and $\mathrm{AIC}_{\mathrm{c}}$ weights $\left(w_{i}\right)$

\begin{tabular}{|c|c|c|c|c|}
\hline \multirow[b]{2}{*}{ Model } & \multicolumn{2}{|c|}{ VI territory level } & \multicolumn{2}{|c|}{ VI core area level } \\
\hline & $\Delta \mathrm{AIC}_{\mathrm{c}}$ & $w_{i}$ & $\mathrm{AIC}_{\mathrm{c}}$ & $w_{i}$ \\
\hline \multicolumn{5}{|l|}{ (a) } \\
\hline Repro $^{\mathrm{a}}$ & 0.00 & 0.78 & 0.00 & 0.86 \\
\hline Null model & 2.54 & 0.22 & 3.56 & 0.14 \\
\hline \multicolumn{5}{|l|}{ (b) } \\
\hline Repro $^{\mathrm{b}}$ & 0.00 & 0.5 & 0.98 & 0.38 \\
\hline Null model & 0.01 & 0.5 & 0.00 & 0.62 \\
\hline \multicolumn{5}{|l|}{ (c) } \\
\hline Null model & 0.0 & 0.82 & 0.00 & 0.82 \\
\hline Age & 3.09 & 0.18 & 3.09 & 0.18 \\
\hline
\end{tabular}

${ }^{\text {a }}$ Model predictions territory level: $\mathrm{VI}=0.53$ for females that successfully reproduced the first year included in overlap estimate, VI $=0.64$ for females that did not reproduce

${ }^{\mathrm{b}}$ Model prediction territory level: VI $=0.64$ for females that successfully reproduced the first year included in overlap estimate, VI $=0.69$ for females that did not reproduce removing these distances, the mean $( \pm \mathrm{SE})$ distance between den sites for stationary females was reduced to $1.8 \pm 0.2 \mathrm{~km}(n=77)$, compared to $2.1 \pm 0.2 \mathrm{~km}(n=79)$. The dashed line indicates the closest distance between neighbouring females den sites used the same year within the study area during the study period (Aronsson 2017)

establishments is the result of a takeover, the inconsistent pattern in LDF is expected, as the focal female could be either an intruding or evicted individual, which was unknown to us in most cases. The latter is supported by the fact that three females that abandoned a territory subsequently exhibited floating behaviour, suggesting that they did not leave because they had the opportunity to obtain a territory of higher quality. Instead, it is likely that they were forced to abandon their territory, possibly because their competitive ability had decreased (Smith 1978), especially considering that two of these females abandoned an area with very high LDF value. Consequently, abandonment of established territories could be related a combination of searching for better territories and social interactions caused by competition for territories.

Another potential explanation for abandonment of territories by adult females is parental investment (Lindström 1986; Berteaux and Boutin 2000). Wolverine natal dispersal pattern is male-biased, where females tend to remain close their natal territory and age at natal dispersal varies more among females than males (Vangen et al. 2001). Young, inexperienced animals that have not settled are often subject to higher mortality than resident animals (Waser 1996; Blankenship et al. 2006). Juvenile wolverine females are killed when they explore areas outside their natal territory after independence, presumably by territorial neighbours (Persson et al. 2003), suggesting that territorial competition can be fierce for young inexperienced females in this saturated area. Hence, parental investment could explain why females vacate 
established territories after a successful reproduction, i.e. they bequeath their territory to a daughter. One of the moving females (F9525) was replaced by her young daughter. Although we did not find any overall effect of age on female fidelity to territory or core area (Table 2c), F9525 was older than all other moving females, and although she was monitored for 3 years after re-establishment, she did not reproduce again (Table 1). Furthermore, females that expanded their territory subsequently covered an area that previously contained two reproducing females, indicating that there are resources for $>1$ female. This could be to secure an area that can later be bequeathed to a female offspring (c.f. budding dispersal in social species; Gardner and West 2006; Nichols et al. 2012). One female (F9986) maintained her expanded territory for 4 years before her adult daughter (F04189) gained possession of half the area. F9986 regained the area again after her daughter died (Fig. 4). In another observation, one subadult daughter established in part of her mother's expanded territory although we could not determine her residency status because she died in an avalanche before first reproduction (27 months of age). The remaining three expanding females did not reproduce $(n=1)$ or only produced male offspring between the expansion and their death or end of the study period $(n=2$, monitored for 2 and 5 years following territory expansion).

To fully understand the causes and consequences of breeding dispersal in wolverine females requires detailed location data to determine the timing and interactions leading up to the dispersal event (i.e. if it is a result of an aggressive interaction). In addition, concurrent data are needed on habitat quality and the reproductive success of stationary versus dispersing adult females. Due to the low reproductive rate of wolverines (Persson et al. 2006) and the rarity of this behaviour, we could not fully disentangle the potential causes despite 20 years of individual-based data.

We suggest that the high territorial fidelity in wolverines in this study is a result of intrasexual territoriality in a saturated population with intense competition for high-quality territories. This is facilitated by scavenging and caching, which increase predictability in resource abundance, decrease depletion rate and create a valuable resource (cache sites) to defend. In addition, distinct terrain features may assist territorial defence, which promote territorial stability in time and space. Our results concur with the findings of Bischof et al. (2016) who investigated spatiotemporal patterns in wolverines using non-invasive genetic sampling to reveal that wolverines tended to stay in the same general area from year to year. We suggest that the ultimate driver of the observed breeding dispersal is high competition for territories, translated through social interactions between competitors (aggressive forcing) and mother-offspring (territory bequeathal). This demonstration of the complexity in carnivore spatial behaviour provides a stronger foundation for science-based management of wolverine populations that are subject to strong conservation and management concerns in many parts of its distribution (Sæther et al. 2005; Persson et al. 2009; Inman et al. 2013). Our results have implications for the design and interpretation of population monitoring schemes (Ellis et al. 2014; Aronsson and Persson 2016), harvest strategies (Sæther et al. 2005) and conflict mitigation (Persson et al. 2015; Aronsson and Persson 2016).

Acknowledgements We thank P. Segerström, T. Wiklund, J.M. Arnemo and E. Segerström for proficient work in the field. M. Low, Ö. Johansson, H. Andrén, L. Nilsson and J. Frank for providing constructive comments on earlier drafts of the manuscript.

Funding information The study was financially supported by the Swedish Environmental Protection Agency, Norwegian Directorate for Nature Management, Swedish Research Council Formas, World Wildlife Fund Sweden, European Association of Zoos and Aquaria, and Marie-Claire Cronstedts Foundation.

Open Access This article is distributed under the terms of the Creative Commons Attribution 4.0 International License (http:// creativecommons.org/licenses/by/4.0/), which permits unrestricted use, distribution, and reproduction in any medium, provided you give appropriate credit to the original author(s) and the source, provide a link to the Creative Commons license, and indicate if changes were made.

\section{References}

Adams ES (2001) Approaches to the study of territory size and shape. Annu Rev Ecol Syst 32(1):277-303. https://doi.org/10.1146/ annurev.ecolsys.32.081501.114034

Aronsson M (2017) O neighbour, where art thou? Spatial and social dynamics in wolverine and lynx, from individual space use to population distribution. $\mathrm{PhD}$ dissertation, Swedish University of Agricultural Sciences

Aronsson M, Persson J (2016) Mismatch between goals and the scale of actions constrain adaptive carnivore management: the case of the wolverine in Sweden. Anim Conserv 20(3):261-269. https://doi. org/10.1111/acv. 12310

Aronsson M, Low M, López-Bao JV, Persson J, Odden J, Linnell JDC, Andrén H (2016) Intensity of space use reveals conditional sexspecific effects of prey and conspecific density on home range size. Ecol Evol 6(9):2957-2967. https://doi.org/10.1002/ece3.2032

Berteaux D, Boutin S (2000) Breeding dispersal in female North American red squirrels. Ecology 81(5):1311-1326.

Bischof R, Gregersen ER, Broseth H, Ellegren H, Flagstad Ø (2016) Noninvasive genetic sampling reveals intrasex territoriality in wolverines. Ecol Evol 6(5):1527-1536. https://doi.org/10.1002/ece3.1983

Blankenship TL, Haines A, Tewes M, Silvy N (2006) Comparing survival and cause-specific mortality between resident and transient bobcats Lynx rufus. Wildl Biol 12(3):297-303.

Börger L, Franconi N, De Michele G, Gantz A, Meschi F, Manica A, Lovari S, Coulson T (2006) Effects of sampling regime on the mean and variance of home range size estimates. J Anim Ecol 75(6):13931405. https://doi.org/10.1111/j.1365-2656.2006.01164.x

Calenge C (2006) The package adehabitat for the R software: a tool for the analysis of space and habitat use by animals. Ecol Model 197(34):516-519. https://doi.org/10.1016/j.ecolmodel.2006.03.017

Clutton-Brock T, Sheldon BC (2010) Individuals and populations: the role of long-term, individual-based studies of animals in ecology and evolutionary biology. Trends Ecol Evol 25:562-573 
Copeland J, McKelvey KS, Aubry KB, Landa A, Persson P, Inman RM, Krebs J, Lofroth E, Golden H, Squires JR, Magoun AJ, Schwartz MK, Wilmot J, Copeland CL, Yates RE, Kojola I, May R (2010) The bioclimatic envelope of the wolverine (Gulo gulo): do climatic constraints limit its geographic distribution? Can J Zool 88(3):233246. https://doi.org/10.1139/Z09-136

Danell AC, Andrén H, Segerström P, Franzén R (2006) Space use by Eurasian lynx in relation to reindeer migration. Can J Zool 84(4): 546-555

Eason PK, Cobbs GA, Trinca KG (1999) The use of landmarks to define territorial boundaries. Anim Behav 58(1):85-91. https://doi.org/10. 1006/anbe.1999.1133

Edwards MA, Nagy JA, Derocher AE (2009) Low site fidelity and home range drift in a wide range, large, Arctic omnivore. Anim Behav 77(1):23-28. https://doi.org/10.1016/j.anbehav.2008.09.025

Eide NE, Jepsen JU, Prestrud P (2004) Spatial organization of reproductive Arctic foxes Alopex lagopus: responses to changes in spatial and temporal availability of prey. J Anim Ecol 73(6):1056-1068. https://doi.org/10.1111/j.0021-8790.2004.00885.x

Ellis MM, Ivan JS, Schwartz MK (2014) Spatially explicit power analyses for occupancy-based monitoring of wolverine in the U.S. Rocky Mountains. Conserv Biol 28:52-62

Flagstad O, Hedmark E, Landa A, Broseth H, Persson J, Andersen R, Segerström P, Ellegren H (2004) Colonization history and noninvasive monitoring of a reestablished wolverine population. Conserv Biol 18(3):676-688. https://doi.org/10.1111/j.1523-1739.2004. 00328.x-i1

Forero MG, Donázar JA, Blas J, Hiraldo F (1999) Causes and consequences of territory change and breeding dispersal in the black kite. Ecology 80(4):1298-1310.

Gardner A, West SA (2006) Demography, altruism, and the benefits of budding. J Evol Biol 19(5):1707-1716. https://doi.org/10.1111/j. 1420-9101.2006.01104.x

Garshelis DL (2000) Delusions in habitat evaluation: measuring use, selection and importance. In: Boitani L, Fuller TK (eds) Research techniques in animal ecology - controversies and consequences. Columbia University Press, New York, pp 111-164

Greenwood PJ (1980) Mating systems, philopatry and dispersal in birds and mammals. Anim Behav 28(4):1140-1162. https://doi.org/10. 1016/S0003-3472(80)80103-5

Greenwood PJ, Harvey PH (1982) The natal and breeding dispersal of birds. Annu Rev Ecol Syst 13(1):1-21. https://doi.org/10.1146/ annurev.es.13.110182.000245

Hedmark E, Persson J, Segerström P, Landa A, Ellegren H (2007) Paternity and mating system in wolverines Gulo gulo. Wildl Biol 13:13-30

Inman RM, Packila ML, Inman KH, Mccue AJ, White GC, Persson J, Aber BC, Orme ML, Alt KL, Cain SL, Fredrick JA, Oakleaf BJ, Sartorius SS (2012a) Spatial ecology of wolverines at the southern periphery of distribution. J Wildl Manag 76(4):778-792. https://doi. org/10.1002/jwmg.289

Inman RM, Magoun AJ, Persson J, Mattisson J (2012b) The wolverine's niche: linking reproductive chronology, caching, competition, and climate. J Mammal 93:34-644

Inman RM, Brock BL, Inman KH, Sartorius SS, Aber BC, Giddings B, Cain SL, Orme ML, Fredrick JA, Oakleaf BJ, Alt KL, Odell E, Chapron G (2013) Developing priorities for metapopulation conservation at the landscape scale: wolverines in the Western United States. Biol Conserv 166:279-286

Isbell LA, Cheney DL, Seyfarth RM (1990) Costs and benefits of home range shifts among vervet monkeys (Cercopithecus aethiops) in Amboseli National Park, Kenya. Behav Ecol Sociobiol 27(5):351358. https://doi.org/10.1007/BF00164006

Jerina K, Pokorny B, Stergar M (2014) First evidence of long-distance dispersal of adult female wild boar (Sus scrofa) with piglets. Eur J Wildl Res 60:367-370
Jetz W, Carbone C, Fulford J, Brown JH (2004) The scaling of animal space use. Science 306(5694):266-268. https://doi.org/10.1126/ science. 1102138

Kirk M, Esler D, Iverson SA, Boyd WS (2008) Movements of wintering surf scoters: predator responses to different prey landscapes. Oecologia 155(4):859-867. https://doi.org/10.1007/s00442-0070947-0

Krebs J, Lofroth E, Copeland J, Banci V, Cooley D, Golden H, Magoun AJ, Mulders R, Shults B (2004) Synthesis of survival rates and causes of mortality in North American wolverines. J Wildl Manag 68:493-502

Lindström E (1986) Territory inheritance and the evolution of groupliving in carnivores. Anim Behav 34(6):1825-1835. https://doi. org/10.1016/S0003-3472(86)80268-8

Maher CR, Lott DF (2000) A review of ecological determinants of territoriality within vertebrate species. Am Midl Nat 143(1):1-29.

Mattisson J, Andrén H, Persson J, Segerström P (2011) Influence of intraguild interactions on resource use by wolverines and Eurasian lynx. J Mammal 92(6):1321-1330. https://doi.org/10.1644/11MAMM-A-099.1

Mattisson J, Segerström P, Persson J, Aronsson M, Rauset GR, Samelius G, Andrén H (2013) Lethal male-male interactions in Eurasian lynx. Mamm Biol 78:304-308

Mattisson J, Rauset GR, Odden J, Andrén H, Linnell JDC, Persson J (2016) Predation or scavenging? Prey body condition influences decision-making in a facultative predator, the wolverine. Ecosphere 7(8):e01407. https://doi.org/10.1002/ecs2.1407

Millspaugh JJ, Gitzen RA, Kernohan BJ, Larson JA, Clay CL (2004) Comparability of three analytical techniques to assess joint space use. Wildl Soc Bull 32(1):148-157.

Moorhouse TP, Macdonald DW (2005) Temporal patters of range use in water voles: do females' territories drift? J Mammal 86(4):655-661.

Nichols HJ, Jordan NR, Jamie GA, Cant MA, Hoffman JI (2012) Finescale spatiotemporal patterns of genetic variation reflect budding dispersal coupled with strong natal philopatry in a cooperatively breeding mammal. Mol Ecol 21(21):5348-5362. https://doi.org/10. 1111/mec. 12015

Pasinelli G, Müller M, Schaub M, Jenni L (2007) Possible causes and consequences of philopatry and breeding dispersal in red-backed shrikes Lanius collurio. Behav Ecol Sociobiol 61(7):1061-1074. https://doi.org/10.1007/s00265-006-0339-1

Pelton MR, van Manen FT (1996) Benefits and pitfalls of long-term research: a case study of black bears in Great Smoky Mountains National Park. Wildl Soc Bull 24:443-450

Penteriani V, Ferrer M, Delgado MM (2011) Floater strategies and dynamics in birds, and their importance in conservation biology: towards an understanding of nonbreeders in avian populations. Anim Conserv 14:233-241

Persson J (2005) Female wolverine reproduction: reproductive costs and winter food availability. Can J Zool 83(11):1453-1459. https://doi. org/10.1139/z05-143

Persson J, Willebrand T, Landa A, Andersen R, Segerström P (2003) The role of intraspecific predation in the survival of juvenile wolverines Gulo gulo. Wildl Biol 9:21-28

Persson J, Landa A, Andersen R, Segerström P (2006) Reproductive characteristics of female wolverines (Gulo gulo) in Scandinavia. J Mammal 87(1):75-79. https://doi.org/10.1644/04-.1

Persson J, Ericsson G, Segerström P (2009) Human caused mortality in an endangered wolverine population. Biol Conserv 142:325-331

Persson J, Wedholm P, Segerström P (2010) Space use and territoriality of wolverines (Gulo gulo) in northern Scandinavia. Eur J Wildl Res 56: $49-57$

Persson J, Rauset GR, Chapron G (2015) Paying for an endangered predator leads to population recovery. Conserv Lett 8(5):345-350. https://doi.org/10.1111/conl.12171 
R Core Team (2014) R: A language and environment for statistical computing. R Foundation for Statistical Computing, Vienna. URL https://www.R-project.org/

Rauset GR, Low M, Persson J (2015) Reproductive patterns result from age-related sensitivity to resources and reproductive costs in a mammalian carnivore. Ecology 96:3153-3164

Sæther B, Engen S, Persson J, Brøseth H, Landa A, Willebrand T (2005) Management strategies for the wolverine in Scandinavia. J Wildl Manag 69(3):1001-1014.

Sandell M (1989) The mating tactics and spacing patterns of solitary carnivores. In: Gittelman JL (ed) Carnivore behavior, ecology, and evolution. Cornell University Press, New York, pp 64-82. https:// doi.org/10.1007/978-1-4757-4716-4_7

Skaug H. et al (2014) Generalized linear mixed models using AD model builder. R package version 0.8.0. http://glmmadmb.r-forge.r-project.org

Smith SM (1978) The "Underwoorld" in a territorial sparrow: adaptive strategy for floaters. Am Nat 112(985):571-582. https://doi.org/10. $1086 / 283298$

Stamps J, Krishnan V (2001) How territorial animals compete for divisible space: a learning-based model with unequal competitors. Am Nat 157(2):154-169. https://doi.org/10.1086/318634

Stephens PA, Pettorelli N, Barlow J, Whittingham MJ, Cadotte MW (2015) Management by proxy? The use of indices in applied ecology. J Appl Ecol 52(1):1-6. https://doi.org/10.1111/1365-2664.12383
Switzer PV (1993) Site fidelity in predictable and unpredictable habitats. Evol Ecol 7(6):533-555. https://doi.org/10.1007/BF01237820

Terraube J, Vasko V, Korpimäki E (2015) Mechanisms and reproductive consequences of breeding dispersal in a specialist predator under temporally varying food conditions. Oikos 124:762-771

Tye A (1986) Economics of experimentally-induced territorial defence in a gregarious bird, the Fieldfare Turdus pilaris. Ornis Scand 17(2): 151-164. https://doi.org/10.2307/3676864

Uboni A, Vucetich JA, Stahler DR, Smith DW (2015) Interannual variability: a crucial component of space use at the territory level. Ecology 96(1):62-70. https://doi.org/10.1890/13-2116.1

Vangen KM, Persson J, Landa A, Andersen R, Segerström P (2001) Characteristics of dispersal in wolverines. Can J Zool 79:1641-1649

Waser PM (1996) Patterns and consequences of dispersal in gregarious carnivores. In: Gittleman JL (ed) Carnivore behaviour, ecology, and evolution, vol 2. Cornell University Press, Ithaca, pp 267-295

Wauters LA, Lens L, Dhondt AA (1995) Variation in territory fidelity and territory shift among red squirrel, Sciurus vulgaris, females. Anim Behav 49:187-193

Worton BJ (1989) Kernel methods for estimating the utilization distribution in home range studies. Ecology 70(1):164-168. https://doi.org/ $10.2307 / 1938423$ 